\title{
METHODOLOGY APPLIED IN MATHEMATHICS FOR HIGH PERFORMANCE STUDENTS
}

\author{
M.D. Teba1, P. Juan', S. Lapeña ${ }^{2}$ \\ ${ }^{1}$ University Jaume I (SPAIN) \\ ${ }^{2}$ IES Professor Broch I Llop, Vila-Real (SPAIN)
}

\begin{abstract}
In this study we present a methodology to satisfy the needs presented by the students with high performance in the Compulsory Secondary Education. This methodology will be part of the "Enrichment Group" and it has some qualities which require the development of their interest and motivation. The cooperative groups alternating master explanations when it is necessary and the use of this methodology in the subject is accompanied by the ICT utilization in the development of activities like the realization of micro videos, use of Kahoots or Flipped Classroom. All these activities not only provide theoretical knowledge but also encourage the ability, skills and creativity to be able to manage autonomously and in groups.
\end{abstract}

In conclusion, we have encouraged the development of their interest and motivation to achieve their maximum potential development, in the way the results are presented.

Keywords: Compulsory Secondary Education, cooperative methodology, Enrichment in Secondary Education, motivation.

\section{INTRODUCTION}

In the classroom, we can find a great variety of students and the necessity to pay attention to the diversity and inclusion. In our case, we present a methodology to satisfy the needs which the students with high performance in the Compulsory Secondary Education present. This methodology will be part of the "Enrichment Group" and it has some qualities which require the development of their interest and motivation.

This methodology needs the implication of teachers for the realization of cooperative work in the classroom, as the Johnson brothers say [1] "Cooperation is working together to accomplish shared goals, being the cooperative learning the didactical use of reduced groups in which students work together to maximize their own learning and the learning of the others. By doing this, favorable relationships, self-esteem, autonomy and other benefits are encouraged amongst students.

The application of flexible groups is necessary in this methodology, since these students have to be in contact with the intellectual diversity that can be found in the classroom and that represents the diversity in society. The students who form the Enrichment group come from two different classrooms of the same year. This fact makes them conscious and encourages the student's diversity. It also leads to inclusiveness.

The students of Enrichment are together in the instrumental subjects, we will particularly focus on the mathematics subject, in which the teacher will follow the cooperative methodology, as J.Vaello quotes [4] "motivation starts by the teacher" (Educational Innovation Classroom).

In this subject, the teacher works with cooperative groups alternating master explanations when it is necessary. Moreover, the use of this methodology in the subject is accompanied by the ICT utilization in the development of activities like the realization of micro videos, use of Kahoots, Flipped Classroom... All these activities not only provide theoretical knowledge but also encourage the ability, skills and creativity to manage autonomously and in groups.

This study is developed in the IES Professor Broll I Llop of Vilareal, Spain, ([5]) with the students of the Enrichment group. 


\section{METHODOLOGY}

We will focus on the methodology of Professor Santi Lapeña in the subject of mathematics with the "Enrichment Group", formed by second course of ESO (Compulsory Secondary Education) students with superior abilities and high performance.

In this Methodology we work on:

a) Cooperative learning

b) Flexible group

\section{A. Cooperative learning:}

The students take a leading role in their learning while being responsible for the learning of classmates, forming small groups in which they work together to obtain common objectives. The role of the teacher staff in this methodology is as a driver, guide and supervisor. This methodology, to be successfully implemented in the classroom, direct and active participation of students is necessary ([1], [2] and [3]).

\section{B. Flexible group:}

Formation of a group following a specific criterion, such as a higher-level group, a group to alleviate certain learning difficulties. This group is maintained only in the instrumental subjects with the aim of motivating and obtaining a greater learning of the students giving a quality response to the different learning rhythms, as well as to the diversity of students. While in the other subjects, contact is maintained with the different student profiles.

The use of this methodology makes the student feel involved in their learning with more motivation and interest, encourages relationships among students, increases self-esteem and autonomy, another very important point is that the students maintain contact with the present reality in the classrooms maintaining the principle of inclusion, while obtaining more individualized attention when working in smaller groups in the instrumental subjects. This is developed in the next referenced webs [4] and [5].

\subsection{Application of the methodology in the enrichment group}

This group is made up of students from two different secondary ESO groups that come together to form a new group, putting into practice a flexible grouping in the instrumental subjects as already mentioned.

The mathematics subject is worked with cooperative groups alternating master explanations when necessary. Working in cooperative group, the layout of the classroom is different since groups are required, the tables are arranged in groups that must be heterogeneous, balanced and of a maximum of four members, ideally three. Each member of the group has a role, with the different roles assigned by the teacher:

Captain (orange in Figures 1 and 2), whose mission is to observe and coordinate the group. He will be responsible for keeping the discussion sheet, writing the works and exercises that are given to the teacher.

Secretary (blue), is the voice of the group. He is responsible for carrying out the exercises on the board. If the teacher asks his group he should be the one to answer for all his classmates.

Moderator (green), is responsible for the volume and the speaking time. He is responsible for maintaining order in the group.

In the event that the group consists of four members there will be two moderators.

The groups are distributed through the classroom, but the captain will be the one facing the blackboard, the secretary will be placed to the right of the captain and in front of him the moderator will be placed, that is to say to the left of the captain. If the group consists of four members, the captain will be placed and in front of him a moderator, on the right side of the captain / another moderator and in front of the secretary. All group members must have a vision of the board. 


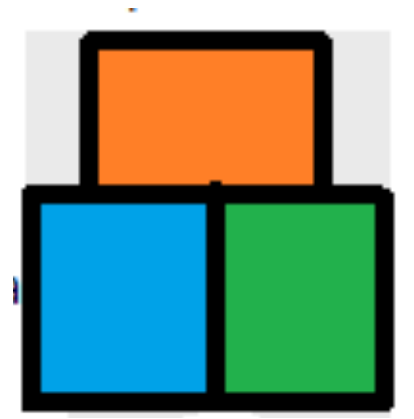

Figure 1. Representation of the position of the different roles in a 3 students group.

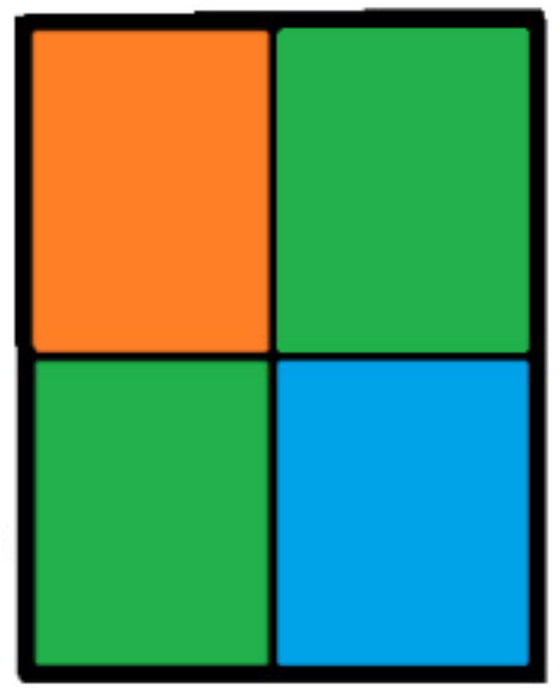

Figure 2. Representation of the position of the different roles in a 4 students group.

Groups and roles are modified every time a new topic begins, the teacher being in charge of their training, always trying to make all the students work with each other and have all adopted the different roles.

The dynamics of the classes is always the same, you start correcting the exercises of the previous day, discuss the solutions obtained and the strategies used in the discussion sheet, this sheet is the worksheet of the group, which the captain custody and this discussion sheet that the teacher uses for the evaluation of group work. The results are commented, it is asked if they have agreed or problems have arisen and sometimes the exercises are carried out on the blackboard by the secretaries of the different groups or by the same teacher. When the teacher sees the alternation in this methodology the use of lectures.

The evaluation is an important point, since the students must be very clear how this evaluation will be carried out by the teacher, for it is explained at the beginning of the course how the evaluation will be carried out, which will be as follows:

The student's grade is obtained from the exams of each subject and everything that is impossible to evaluate with the objective tests. This second part represents $30 \%$ of the grade in second course of ESO and includes aspects as diverse as, for example:

- Explain to the other classmates in the group.

- Listen to the other classmates in the group.

- Play a role well.

- Encourage others to play their role well.

- Have critical thinking.

- Work as a team.

- Make the videos. 
- Make and correct homework.

- Use the discussion sheet.

Each one of these aspects has a weight and is evaluated through a rubric, in addition each student receives three evaluations:

- Self-evaluation

- Co-evaluation of the rest of the group members

- Teacher evaluation

The weights assigned to each part is an aspect that the professor has to decide, but a possible weighting could be:

Self-evaluation (10\%), co-evaluation (40\%) and teacher evaluation $(50 \%)$.

It must also be borne in mind that in this methodology the teacher is very aware of the new technologies and uses them in the classes, the students perform as activities micro-videos, kahoots, flipped classroom... and the promotion of mathematical culture with excursions, mathematical routes, Mathematical competitions, ...

The objectives that are to be obtained with the application of this methodology in the Enrichment Group:

- Give an educational response to students with high abilities and/or high performance.

- Attend to the diversity of students respecting the principles of normalization and inclusion.

- Enhance the abilities and abilities of the students.

- Encourage students' motivation and interest in the mathematics subject.

- Promote interaction between students and between the student/teacher.

- Promote the autonomy of students, both individually and as a group.

- Incorporate the use of ICT's, in order to train students in the digital competence.

- Achieve a socializing learning environment.

- Develop a critical, logical and creative thinking.

In order to evaluate all the results obtained, a survey is carried out with the students of the second course of ESO of the Enrichment Group, with which they try to obtain an assessment about the methodology and its application in the subject from the experience and perception of the students. For this study, 12 questions were presented and evaluated from 1 to 5 , being 1 "Totally disagree or nothing" and 5 "Totally agree or much".

\begin{tabular}{|c|c|c|c|c|c|}
\hline Questions: & 1 & 2 & 3 & 4 & $\mathbf{5}$ \\
\hline 1. The methodology used makes me the most motivating work. & & & & & \\
\hline $\begin{array}{l}\text { 2. This methodology allows to help the other members of the group to overcome the } \\
\text { difficulties. }\end{array}$ & & & & & \\
\hline $\begin{array}{l}\text { 3. I believe that with the use of this methodology the work assumed by the students is } \\
\text { greater. }\end{array}$ & & & & & \\
\hline $\begin{array}{l}\text { 4. This methodology facilitates the involvement of all students in the resolution of } \\
\text { tasks. }\end{array}$ & & & & & \\
\hline 5. The class is well organized. & & & & & \\
\hline 6. The materials and explanations are adequate. & & & & & \\
\hline 7. The results obtained are in accordance with the work done. & & & & & \\
\hline 8. Group work creates more conflicts. & & & & & \\
\hline 9. The teacher guides and helps when necessary in the tasks. & & & & & \\
\hline 10. The evaluation criteria are clear. & & & & & \\
\hline 11. New technologies are used in classes and assignments & & & & & \\
\hline 12. I would recommend this methodology. & & & & & \\
\hline
\end{tabular}




\section{RESULTS}

As results, from the survey of student satisfaction with respect to the applied methodology, we can see the total graph of the notes (Figure 3).

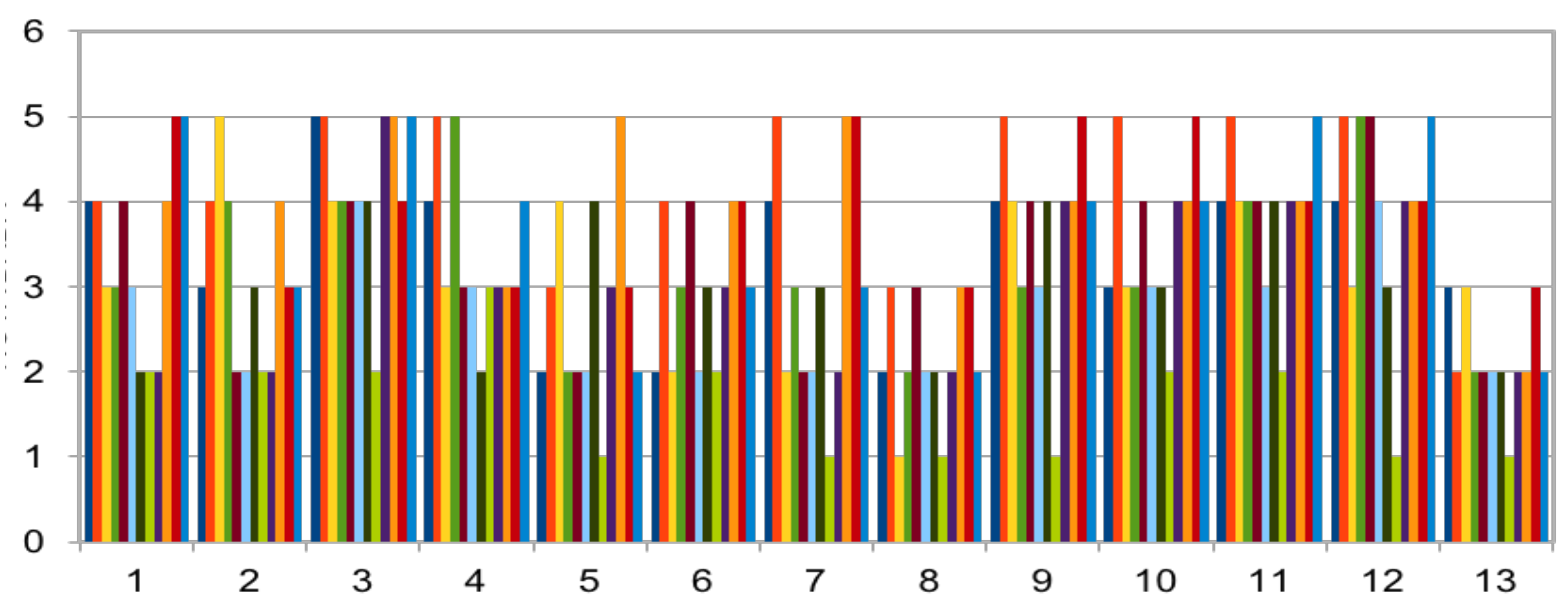

Figure 3. Representation of the response of the 13 students with assessment from 1 to 5 for each question.

Based on the answers, the results obtained are analyzed:

As example, for question 1: Does the methodology used make me work more motivating?

After analyzing the results, it can be concluded that for the majority of the students the use of this methodology makes them feel motivated in the classrooms in the mathematics subject (Figures 4 and $5)$.

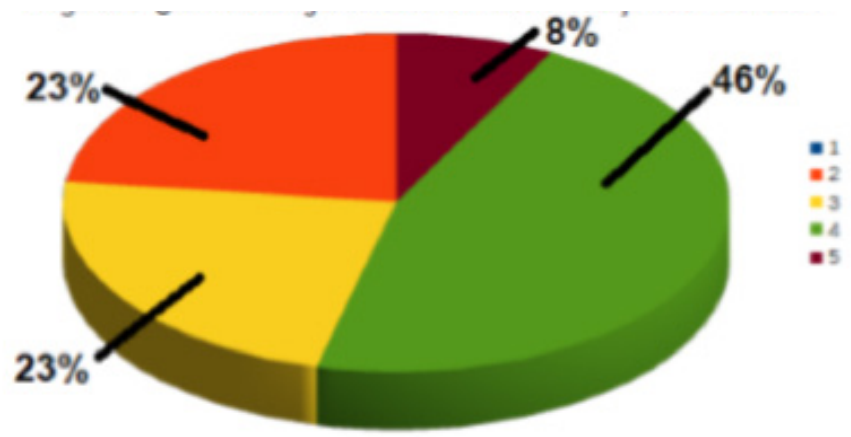

Figure 4: Representation in percentage of the results of the first question.

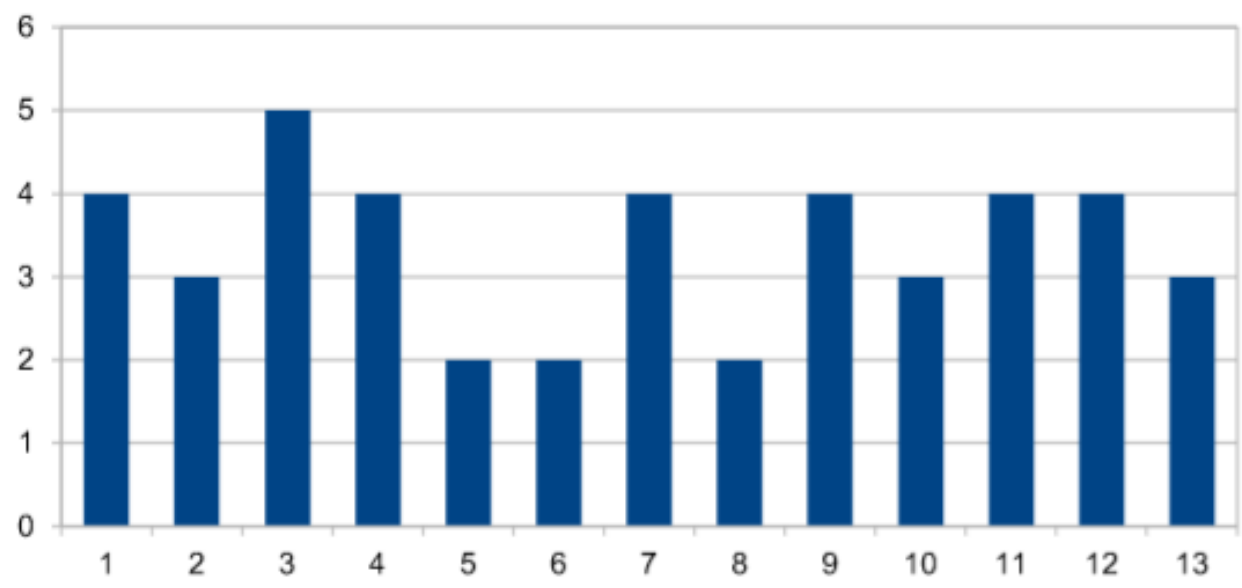

Figure 5. Score of each student to the first question. 
The same procedure is used to analyze each of the 12 questions that make up the questionnaire.

After all the analysis of the set of questions, it is extracted that the majority of the students consider that the use of this methodology allows them to help the other members of the group to overcome the difficulties, since they have more contact with the classmates when working in small groups and this facilitates communication, as well as the detection by different members of the possible difficulties of their peers. This contact makes it possible for them to help themselves overcome difficulties. In addition, they consider that they assume more work with the use of this methodology is to be expected because this methodology requires the active involvement of the students for a correct and positive development.

\section{CONCLUSIONS}

We can say that it is necessary for teachers to know the type of students that are in the classrooms and give them a quality education that responds to their needs.

The purpose of the exposed methodology is to enhance the abilities and skills of high performance students and/or high abilities, achieving a greater motivation and interest in learning since they are more involved avoiding disconnect and/or bored in the classroom.

The majority of the students consider that group work does not create conflicts, since this group work allows them to give their opinion and learn to listen and respect the opinions of the rest of their classmates, as well as to debate and agree on the differences with respect and that this methodology provides that students work with more autonomy, the teacher is not a mere transmitter of knowledge, but the student is sought to be involved in their learning and that of their classmates.

It is also important to emphasize that the students consider that the evaluation criteria are clear and that new technologies are present both in the class and in the tasks.

This methodology needs a great involvement and work on the part of the teacher as well as the students, since without the participation and interest of the two parties, the process could not be carried out.

As an important conclusion is that most students would recommend this methodology.

\section{ACKNOWLEDGEMENTS}

The authors thanks to the University Jaume I of Castellón of Educational Support Projects (ININIMESMA, reference 3425).

\section{REFERENCES}

[1] Johnson, D., Johnson, R. y Holubec, E. (1999). El aprendizaje cooperativo en el aula. Barcelona: Ediciones Paidós Ibérica S.A.

[2] Pujolàs, P. (2009). Aprendizaje Cooperativo y Educación Inclusiva: Una forma práctica de aprender juntos alumnos diferentes. Universidad de Vic.

[3] Torrego Seijo, Juan Carlos et al. (2011). Alumnos con altas capacidades y aprendizaje cooperativo. Un modelo de respuesta educativa.

[4] Vaello, Joan (2011). Aula de Innovación Educativa, núm. 205. Pp. 65-70. Graó. Recuperado en http://www.grao.com/revistas/aula/205-lenguas-integradas-y-competencias-basicas/joan vaellono-hay-problemas-hay-retos-eay-retos-el-problema-te-paraliza-el-reto-te-estimula.

[5] Web of IES Professor Broch I Llop de Vilareal: http://iesbrochillop.edu.gva.es

[6] https://sites.google.com/site/mastermatesuji Material of Santi Lapeña

[7] https://sites.google.com/site/uji2017ac Material of Santi Lapeña 